\title{
Functional outcome of diaphyseal humerus fractures treated with LC- DCP and intramedullary nail - a comparative study
}

\author{
Elango $\mathbf{M}^{1}$, Manoharan $\mathbf{M}^{2}$, Sureshraj $\mathbf{P}^{3}$, Justin Moses $\mathbf{C}^{4}$, Murugan $\mathbf{A}^{5}$ \\ ${ }^{1}$ Dr Elango M, MS Ortho, Associate Professor, ${ }^{2}$ Dr Manoharan M, MS Ortho, Assistant Professor, ${ }^{3}$ Dr Sureshraj P, D \\ Ortho, Junior Resident, ${ }^{4}$ Dr Justin Moses C, MS Ortho, Assistant Professor, ${ }^{5}$ Dr Murugan A, MS Ortho, Professor \& \\ Head. All are affiliated with Department of Orthopaedics, Manakula Vinayagar Medical College \& Hospital, Puducherry, \\ India.
}

Address for correspondence: Dr Manoharan M, Email: drmmanoharan @ yahoo.com

\begin{abstract}
Background: Diaphyseal humerus fractures are not uncommon in orthopedics; accounting for approximately $3 \%$ of all fractures and represent $20 \%$ of all humeral fractures. Most of the humeral shaft fractures are best treated non-operatively with fairly high union rates. With recent advances, encouraging results following internal fixation had led to the expansion of surgical indications. But again the right procedure and implant of choice, remains controversial. Usual surgical modalities include compression plating (DCP) and intramedullary nailing (IMN). Literature review states that previous studies comparing these two implants have came out with varying results. Objective: The objective of this study is to compare the functional outcome of adult diaphyseal humerus fractures treated by limited contact dynamic compression plating and intramedullary interlocked nailing. Materials and Methods: We prospectively randomised twenty eight patients with closed diaphyseal humerus fractures presented to our hospital, over a period of two years and operated with either limited contact dynamic compression plate (LC-DCP) or Intramedullary interlocked nail (IMIL). A minimum of six months follow-up period was completed only by twenty four patients with twelve in each group. Functional scoring was done based on the Rodriguez-Merchan criteria at 4, 8, 12 and 24 weeks for all the patients. Results \& Conclusion: Our findings showed subtle differences favouring the nailing group, yet statistically it turned out to be insignificant. We conclude that none of the implant is superior to other, in terms of fracture union and functional outcome. Hence the implant choice should be at the discretion of the operating surgeon.
\end{abstract}

Key words: Diaphyseal Humerus Fractures, Intramedullary Nailing, LC-DCP

\section{Introduction}

Diaphyseal humerus fractures are not uncommon in orthopaedics, accounting for approximately $3 \%$ of all fractures and represent $20 \%$ of all humeral fractures [13]. These fractures are a significant burden to the society, in terms of loss in productivity and wages [4]. The incidence in a year was about 10 in $100,000 .^{2}$ Most of them were closed fractures occurring in the males of third to fifth decade, with commonest mode of injury being the road traffic accidents [2].

Charnley stated that, "It is perhaps the easiest of all the major long bones to treat by conservative methods" [1]. Most of the humeral shaft fractures are best treated non-

Manuscript received: $24^{\text {th }}$ Oct 2015

Reviewed: $4^{\text {th }}$ Nov 2015

Author Corrected: $14^{\text {th }}$ Nov 2015

Accepted for Publication: $18^{\text {th }}$ Nov 2015 operatively with fairly high union rates [5, 6]. However not all humeral shaft fractures are eligible for conservative treatment and indications for operative management in some situations remains apart [7, 8].

Historically used methods of conservative treatment include skeletal traction, abduction cast, coaptation splint, velpeau dressing, and hanging arm cast. All has its own advantages and disadvantages like joint stiffness and also it needs long period of rehabilitation to restore motion in the immobilized joints [8-10]. With recent advances, encouraging results following internal fixation had led to the expansion of surgical indications [11]. But again the right procedure and implant of choice, remains controversial $[6,11]$. Surgical stabilization can be achieved with different implants. Usual surgical modalities include dynamic compression 
plating (DCP) and intramedullary nailing (IMN) [12, 13]. Previous studies compared these two implants and came out with varying results [14-16].

After inception of the new concept of biological internal fixation, limited contact dynamic compression plating (LC-DCP) was found to be superior compared to the DCP [17-19]. To the best of our knowledge, only few studies in the literature purely compared the results of LC-DCP with IMIL in diaphyseal humerus fractures. Hence we hereby proposed a prospective study on the functional outcome of closed diaphyseal humerus fractures managed by limited contact dynamic compression plating (LC-DCP) and intramedullary interlocked nailing (IMIL).

\section{Materials and Methods}

prospective and comparative study on the functional outcome of adult diaphyseal humerus fractures treated by limited contact dynamic compression plating and intramedullary interlocked nailing was undertaken in the department of orthopaedics, at our institute over a period of two years from Oct 2012 to Oct 2014 with a minimum follow-up of 6 months.

During the above mentioned period, all consecutive patients presented with acute closed diaphyseal humerus fractures to the casualty and orthopedic OPD, fitting to the criteria were all included. Diaphyseal humerus fracture was defined as fractures of the humerus located $3 \mathrm{~cm}$ distal to the surgical neck of humerus and $5 \mathrm{~cm}$ proximal to the olecranon fossa.

Based on the previous inflow of patients and from previous studies, diaphyseal humerus fractures accounting for $1-3 \%$ of all fractures, total sample size was aimed as 30 patients with 15 patients in each group [1]. All the patients with diaphyseal humerus fractures, presented to our hospital were allocated to each group based on computer generated random numbers.

The inclusion criteria were:

1. Closed diaphyseal fractures of the Humerus.

2. Less than 2 weeks old from the date of injury.

3. Patients from 18 years to 70 years and

4. Polytrauma.

The exclusion criteria were: 1 . Patients who are less than 18 years and more than 70 years, 2. Patients with open injuries and segmental fractures, 3. Pathological fractures \& Refractors [12], 4. Old neglected humerus fractures [12].

All patients satisfying the inclusion criteria were assessed both clinically and radiologically (two views) before the decision for surgical intervention is made. All fractures were classified according to Arbeitschemeinschaftfur Osteosynthesefragen classification. Thorough evaluation of the patient was done pre-operatively for neurovascular status and associated injuries. Until surgery, the limb was immobilised in a U slab and pouch arm sling.

Institutional Ethics Committee clearance was obtained prior to the initiation of the study. The operative procedure and expected complications were explained to the patient with a printed patient information document and informed written consent (in patients own language) was obtained from the patient both for surgery and participation in the study. The patients posted for surgery were subjected to routine investigations required for any orthopaedic procedure. Pre-anesthetic fitness was obtained and after reserving adequate blood, patient will be taken for surgery. All the patients were operated by surgeons familiar to both the procedures. After randomisation, twenty eight patients were operated with LC-DCP or IMIL nail according to the group in which they are allotted.

Of the twenty eight patients, fifteen have undergone plating with LC-DCP. Based on the position of the fracture either anterolateral or posterior approach was used for implanting the LC-DCP. In all the plated cases we used a narrow $4.5 \mathrm{~mm}$ LC-DCP made of stainless steel and a minimum of 8 cortices were engaged with screws in each fragments [Figure 1 \& 2]. Remaining thirteen patients have undergone antegrade intramedullary interlocked nailing by deltoid splitting approach. In all the nailing cases both proximal and distal locking was done [Figure $3 \& 4$ ].

Immediately following the surgery the limb was supported with pouch arm sling. Irrespective of the surgery done, gradual shoulder and elbow mobilization exercises were started from the second post-operative day (POD). The drain was removed by 48 hours. Suture removal was done on $12^{\text {th }}$ POD.

All the patients were followed up for a minimum of 6 months. Radiographs in two views for assessing the fracture union was taken and the functional results with complications were all assessed and recorded using Rodriguez-Merchan criteria at 2 weeks, 4 weeks, 8 
weeks, 12 weeks and 24 weeks for all the patients. As per the criteria, the overall rating of the functional outcome was classified into excellent, good, fair and poor outcome based on the scores of shoulder and elbow movements along with pain and disability after the procedure. In situations where any of the two different criteria fell into separate categories the lowest category was selected to classify the outcome.

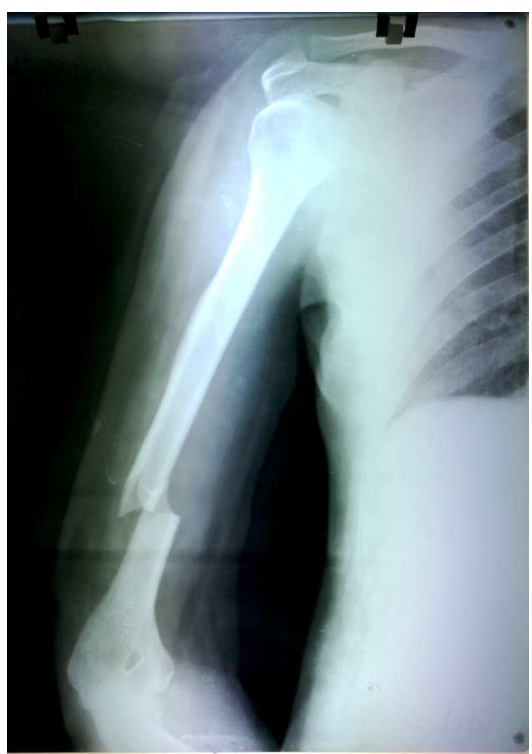

Figure 1: Pre-Operative Radiograph

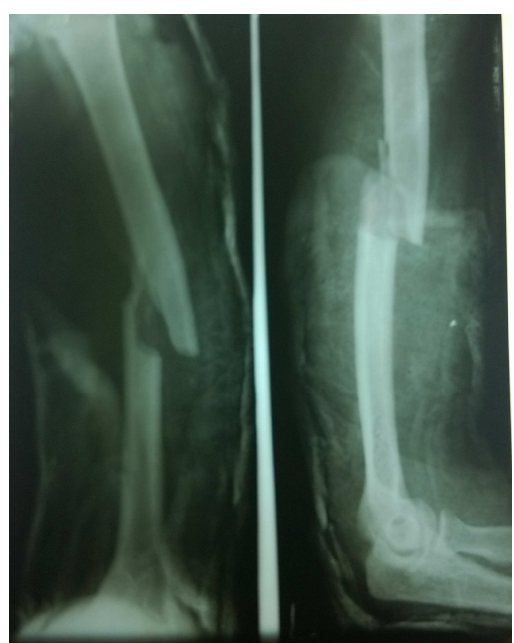

Figure 3: Pre-Operative Radiograph

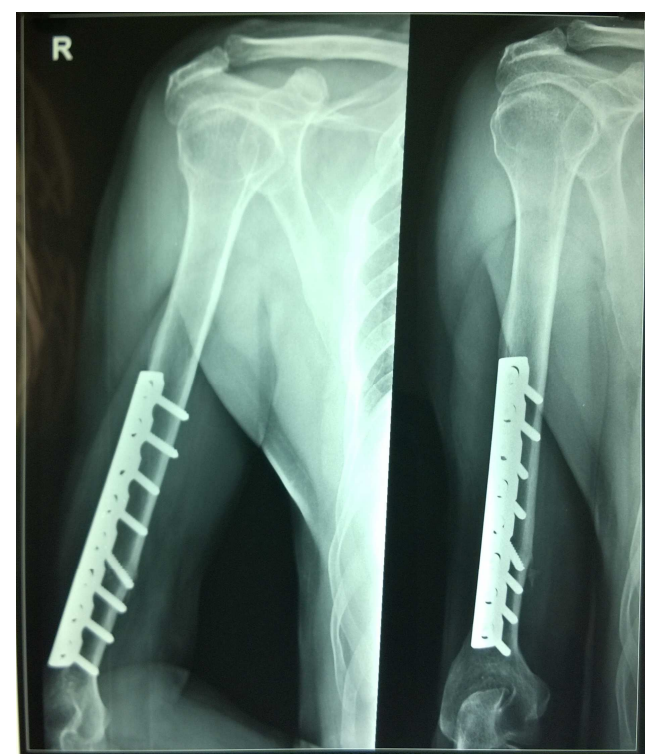

Figure 2: Six months Follow-up Radiograph (LC-DCP)

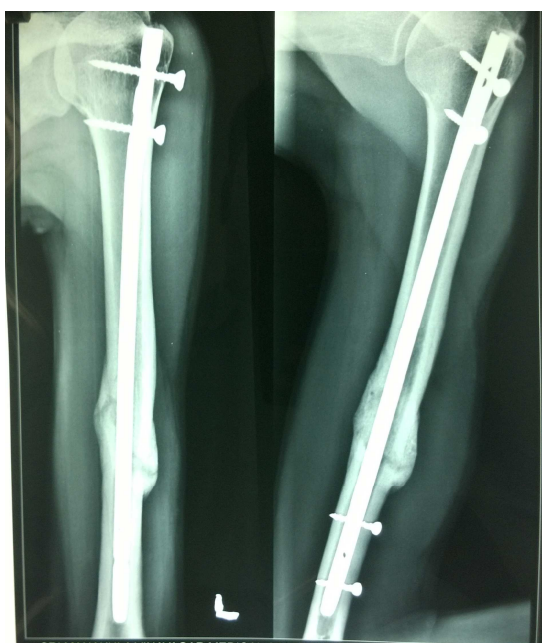

Figure 4: Six months Follow-up Radiograph (ILN)

Regarding the fracture union, tri-cortical union seen in two radiological views were considered united. Duration less than or equal to 12 weeks was considered as normal union, more than 12 weeks up to 24 weeks was considered as delayed union and more than 30 weeks was considered as non union.

Data obtained was coded and entered into Microsoft excel spreadsheet. A probability value (p value) of less than or equal to 0.05 was considered as statistically significant. Frequencies tables were generated and percentage was also calculated for all variables using SPSS (Software Package for Statistical solutions), v16.0, Illinois, Chicago. The test of significance was calculated by applying chi-square test. Charts and graphs were generated using Microsoft excel spreadsheet. 


\section{Results}

There were 28 patients with diaphyseal humerus fractures presented to our hospital during the course of the study. All the patients were operated. Four patients lost follow-up. The remaining 24 patients were taken up for the final analysis. Of the 24 patients, 12 patients belonged to the LC- DCP and 12 patients belonged to the nailing group [Table 1].

\section{Table 1: Distribution of patients}

\begin{tabular}{|l|l|l|l|}
\hline & LC-DCP & ILN & Total \\
\hline No. Of Patients & $12(50 \%)$ & $12(50 \%)$ & $24(100 \%)$ \\
\hline Gender & $11(91.7 \%)$ & $7(58.3 \%)$ & $18(75 \%)$ \\
\hline Male & $1(8.3 \%)$ & $5(41.7 \%)$ & $6(25 \%)$ \\
\hline Female
\end{tabular}

* - Limited contact dynamic compression plating

$\dagger-$ Intramedullary Interlocked Nail

\section{Table 2: Mode of Injury}

\begin{tabular}{|l|l|l|l|}
\hline MOI & LC-DCP & ILN & Total \\
\hline \multirow{2}{*}{ RTA } & 7 & 8 & 15 \\
& $(58.3 \%)$ & $(66.7 \%)$ & $(62.5 \%)$ \\
\hline \multirow{2}{*}{ Self Fall } & 5 & 4 & 9 \\
& $\backslash(41.7 \%)$ & $(33.3 \%)$ & $(37.5 \%)$ \\
\hline \multirow{2}{*}{ Total } & 12 & 12 & 24 \\
& $(100 \%)$ & $(100 \%)$ & $(100 \%)$ \\
\hline
\end{tabular}

$\ddagger-$ Mode of injury, $\S-$ Road Traffic Accident

The youngest patient in our study was 18 years old while the oldest was 60 years old. The maximum incidence was noted between 51-60 years of age group. Males accounted for 75\% of cases and road traffic accidents (62.5\%) topped the mode of injury followed by sell fall [Table 2]. Almost $60-70 \%$ of the patients are teetotallers and almost $70 \%$ had no comorbidities. Two patients had hypertension, two patients had diabetes mellitus and other co-morbidities include bronchial asthma, obesity and hypothyroidism with one patient in each condition. No obvious side predilection was noted regarding the Laterality of the fracture. All the fractures could be classified under AO types A \& B. Among all fracture types A3 $(50 \%)$ topped the list [Table 3].

Table 3: Distribution of AO fracture types

\begin{tabular}{|l|l|l|l|}
\hline AO Type & LC-DCP & ILN & Total \\
\hline A1 & $1(8.3 \%)$ & $0(0 \%)$ & $1(4.2 \%)$ \\
\hline A2 & $2(16.7 \%$ & $2(16.7 \%)$ & $4(16.7 \%)$ \\
\hline A3 & $9(75 \%)$ & $3(25 \%)$ & $12(50 \%)$ \\
\hline B1 & $0(0 \%)$ & $2(16.7 \%)$ & $2(8.2 \%)$ \\
\hline B2 & $0(0 \%)$ & $4(33.3 \%)$ & $4(16.7 \%)$ \\
\hline B3 & $0(0 \%)$ & $1(8.3 \%)$ & $1(4.2 \%)$ \\
\hline C1,C2 \& C3 & $0(0 \%)$ & $0(0 \%)$ & $0(0 \%)$ \\
\hline Total & $12(100 \%)$ & $12(100 \%)$ & $24(100 \%)$ \\
\hline
\end{tabular}

A1-Simple spiral, A2-Simple oblique, A3-Simple transverse, B1-Spiral Wedge, B2- Bending Wedge, B3-Fragmented Wedge, C-Complex fracture type

All patients in the LC-DCP group underwent open reduction and in nailing group, 75\% patients underwent closed reduction and only $25 \%$ needed open reduction. Intra operatively, guide wire insertion difficulty was present in two patients of the nailing group. 
Regarding the time for union, by 12 weeks $75 \%$ of the nailing group achieved radiological union compared to $66.7 \%$ in LC-DCP group. In nailing group only $25 \%$ took more than 12 weeks to achieve radiological union compared to $33.3 \%$ in plating group [Table 4]. Though it appears that healing rate is relatively faster in nailing group, no statistical significance was noted $(\mathrm{p}=0.65)$.

\section{Table 4: Radiological Union}

\begin{tabular}{|c|c|c|c|c|}
\hline Union Achieved & LC-DCP & IMIL & Total & Test of Significance \\
\hline$\leq 12$ weeks & $\begin{array}{l}8 \\
(66.7 \%)\end{array}$ & $\begin{array}{l}9 \\
(75 \%)\end{array}$ & $\begin{array}{l}17 \\
(70.8 \%)\end{array}$ & \multirow{3}{*}{$\begin{array}{l}\mathrm{P}=0.65 \\
\text { (chi-square test) }\end{array}$} \\
\hline$>12$ weeks & $\begin{array}{l}4 \\
(33.3 \%)\end{array}$ & $\begin{array}{l}3 \\
(25 \%)\end{array}$ & $\begin{array}{l}7 \\
(29.2 \%)\end{array}$ & \\
\hline Total & $\begin{array}{l}12 \\
\backslash(100 \%)\end{array}$ & $\begin{array}{l}12 \\
(100 \%)\end{array}$ & $\begin{array}{l}24 \\
(100 \%)\end{array}$ & \\
\hline
\end{tabular}

Regarding complications, one patient in LC-DCP group had pre-operative radial nerve palsy and on exploration the nerve was found to be intact. It recovered in about three months. One patient in LC-DCP group had shoulder stiffness and two patients had delayed union. Where as in nailing group, 2 patients had delayed union and two patients developed post operative radial nerve palsy, which all recovered subsequently in three months. No statistical significance could be noted between the two groups [Table 5].

\section{Table 5: Complications}

\begin{tabular}{|c|c|c|c|c|}
\hline Complications & LC-DCP & ILN & Total & Test of Significance \\
\hline Nil & $\begin{array}{l}9 \\
(75 \%)\end{array}$ & $\begin{array}{l}8 \\
(66.6 \%)\end{array}$ & $\begin{array}{l}17 \\
(70.8 \%)\end{array}$ & \multirow{5}{*}{$\begin{array}{l}\mathrm{P}=0.38 \\
\text { (chi-square test) }\end{array}$} \\
\hline Delayed Union & $\begin{array}{l}2 \\
(16.7 \%)\end{array}$ & $\begin{array}{l}2 \\
(16.7 \%)\end{array}$ & $\begin{array}{l}4 \\
(16.7 \%)\end{array}$ & \\
\hline Radial N Palsy & $\begin{array}{l}0 \\
(0 \%)\end{array}$ & $\begin{array}{l}2 \\
(16.7 \%)\end{array}$ & $\begin{array}{l}2 \\
(8.3 \%)\end{array}$ & \\
\hline Shoulder Stiffness & $\begin{array}{l}1 \\
(8.3 \%)\end{array}$ & $\begin{array}{l}0 \\
(0 \%)\end{array}$ & $\begin{array}{l}1 \\
(4.2 \%)\end{array}$ & \\
\hline Total & $\begin{array}{l}12 \\
(100 \%)\end{array}$ & $\begin{array}{l}12 \\
(100 \%)\end{array}$ & $\begin{array}{l}24 \\
(100 \%)\end{array}$ & \\
\hline
\end{tabular}

According to the Rodriguez Merchan criteria functional results were assessed [Table 6]. Among the 24 patients, 12 had excellent results with 7 patients in ILN group and 5 patients in LC-DCP group. 10 patients had good results with 5 patients in each group and 2 patients had poor results which belong to the plating group [Table 7]. On statistical analysis, no significant difference was noted between the LC-DCP and ILN group ( $p=0.31$ ).

Table 6: Rodriguez-Merchan Criteria[11, 19]

\begin{tabular}{|l|l|l|l|l|l|}
\hline \multirow{2}{*}{ Rating } & Elbow ROM & \multirow{2}{*}{ Shoulder ROM } & \multirow{2}{*}{ Pain } & \multirow{2}{*}{ Disability } \\
\cline { 2 - 5 } & Flexion & Extension & & & None \\
\hline Excellent & $130^{\circ}$ & $5^{\circ}$ & Full Range & None & Minimum \\
\hline Good & $120^{\circ}$ & $15^{\circ}$ & $<10 \%$ Loss & Occasional & Moderate \\
\hline Fair & $110^{\circ}$ & $30^{\circ}$ & $10-30 \%$ Loss & With Activity & Severe \\
\hline Poor & $90^{\circ}$ & $40^{\circ}$ & $>30 \%$ Loss & Variable & \\
\hline
\end{tabular}


Table 7: Functional Results Compared

\begin{tabular}{|c|c|c|c|c|}
\hline Rating & LC-DCP & ILN & Total & Test of Significance \\
\hline Excellent & $\begin{array}{l}5 \\
(41.7 \%)\end{array}$ & $\begin{array}{l}7 \\
(58.3 \%)\end{array}$ & $\begin{array}{l}12 \\
(50 \%)\end{array}$ & \multirow{5}{*}{$\begin{array}{l}\mathrm{P}=0.31 \\
\text { (chi-square test) }\end{array}$} \\
\hline Good & $\begin{array}{l}5 \\
(41.7 \%)\end{array}$ & $\begin{array}{l}5 \\
(41.7 \%)\end{array}$ & $\begin{array}{l}10 \\
(41.7 \%)\end{array}$ & \\
\hline Fair & $\begin{array}{l}2 \\
(16.6 \%)\end{array}$ & $\begin{array}{l}0 \\
(0 \%)\end{array}$ & $\begin{array}{l}2 \\
(8.3 \%)\end{array}$ & \\
\hline Poor & $\begin{array}{l}0 \\
(0 \%)\end{array}$ & $\begin{array}{l}0 \\
(0 \%)\end{array}$ & $\begin{array}{l}0 \\
(0 \%)\end{array}$ & \\
\hline Total & $\begin{array}{l}12 \\
(100 \%)\end{array}$ & $\begin{array}{l}12 \\
(100 \%)\end{array}$ & $\begin{array}{l}24 \\
(100 \%)\end{array}$ & \\
\hline
\end{tabular}

\section{Discussion}

The goal of fracture management is restoration of physiological function at the earliest [20]. Conservative treatment of humeral shaft fractures represents an effective method of fracture management and has sustained critical evolution throughout the literature [8, 20]. However the incidence of non-union, malunion, residual angulation, limb length inequality and significant loss of function were shown to be high with non operative management.

Newer studies and surgical experiences say that operative treatment may be applied to more cases of humeral diaphyseal fractures than has historically been thought $[8,14,20]$. Further, operative treatment is proven to have greater strength, with improved functional outcome and earlier return to work at 6 weeks [21]. As a result, patient factors are gaining more importance, leading to doctor patient discussions weighing the benefits of early mobilisation, rapid return to job and pain control versus the risk of iatrogenic radial nerve palsy, infection, blood loss, reoperation and anaesthetic risk [22].

This prospective study was done to evaluate the functional outcome of limited contact dynamic compression plating and intramedullary interlocked nailing in diaphyseal humerus fractures of adults. We evaluated the results of this study and compared them with previous studies. The average age of patients in LC-DCP and nailing groups were 40.67 and 41.58 respectively. This finding was similar to the observations of Ragahavendra S et al [6], Mc Cormack $\mathrm{R}$ G et al [14], Benegas E et al [23], and Shah SM et al [24]. There was male preponderance noted in this study, which is also observed in all the other studies. The commonest mode of injury (MOI) is the road traffic accident $(62.5 \%)$. Similar MOI was noted in all the studies compared. The next commonest is the self fall (37.5\%) which is consistent with Raghavendra $S$ et al [6]. In our study, the commonest site of the fracture is the middle third humerus $(75 \%)$. This finding was consistent with Raghavendra $\mathrm{S}$ et al [6], Singisetti K et al [11] and Shah S M et al [24]. In our study, the commonest AO fracture type is A3 $(50 \%)$. Similar finding was noted in Singisetti $\mathrm{K}$ et al [11], Kesemenli C C et al [25], and Venkatesh Gupta S $\mathrm{K}$ et al [26].

In our study, the minimum follow up period was 6 months. Similar findings were noted in Changulani M et al [12], McCormack R G et al [14], and Benegas E et al [23].

In our study, $66.7 \%$ of the plating group united in less than 12 weeks, where as $75 \%$ of the nailing group united in less than 12 weeks. There is no statistical significance noted in the fracture union between the two groups. Similar statistical insignificance was noted in Raghavendra S et al [6], McCormack R G et al [14], Benegas E et al [23], Shah S M et al [24], Kesemenli C $\mathrm{C}$ et al [25], and Venkatesh Gupta S K et al [26].

In our study, nailing group had $16.7 \%$ iatrogenic radial nerve injury but plating group had no iatrogenic radial nerve injury. Similar finding was noted in McCormack $R$ G et al [14]. But in Singisetti $K$ et al [11] and Kesemenli C C et al [25] iatrogenic radial nerve injury was noted only in plating group and not in nailing group.

In our study, the incidence of delayed union (16.7\%) was similar in both plating and nailing group. Almost similar findings were noted in Venkatesh Gupta SK et al [26] and Denies E et al [27]. 
In our study, $8.3 \%$ of the plating group had restricted shoulder movements, where as nailing group had no such complication. This finding is similar to Singisetti $\mathrm{K}$ et al [11] and Venkatesh Gupta $S$ et al [26]. Contrary to this, Changulani $\mathrm{M}$ et al [12], McCormack $\mathrm{R} \mathrm{G}$ et al [14], Shah S M et al [23], Kesemenli C C et al [25] and Denies $\mathrm{E}$ et al [27] had more number of restricted shoulder movements with the nailing group. In our study, no other complications like infection, non union, implant failure and secondary surgery were recorded.

In our study, Rodriguez Merchan criteria were employed to assess the functional outcome. Similar criteria were used in Singisetti K et al [11] study. In our study, no statistical significance was noted in the final functional outcome between the two groups. Similar finding was noted in Raghavendra S et al [6], Singisetti $\mathrm{K}$ et al [11], Changulani M et al [12], McCormack R G et al [14], Benegas E et al [23], Shah S M et al [24], Kesemenli C C et al [25], Venkatesh Gupta S K et al [26] and Denies E et al [27].

Among all the similar studies compared, though no statistical significance exist between the plating and nailing groups, four studies suggested plating as better option and four studies suggested nailing as better option for various reasons. One study said implant option should be of the operating surgeon's choice [23].

\section{Conclusion}

In this prospective study conducted at our hospital from Oct 2012 to Oct 2014, we found that both the treatment modalities, i.e. limited contact dynamic compression plating and intramedullary interlocking nailing were equal with respect to the radiological union and complications concerned. In this study, only subtle differences were noted in the functional outcome favouring the nailing group, which also turned out to be statistically insignificant.

The fallacy in this study was the small sample size. We conclude saying that, none of the implant is found to be superior to the other, in terms of fracture union and functional outcome. Hence the implant option should be at the discretion of the operating surgeon, unless some specific indication for a particular implant is present.

Funding: Nil, Conflict of interest: None.

Permission of IRB: Yes

\section{Bibliography}

1. Crenshaw AH., Jr, Perez EA. Fractures of shoulder, arm and forearm. In: Canale ST, Beaty JH eds. Campbell's Operative Orthopaedics. $11^{\text {th }}$ ed. Philadelphia: Mosby Elsevier; 2008;3:3389-98.

2. Tsai $\mathrm{CH}$, Fong $\mathrm{YC}$, Chen $\mathrm{YH}$, Hsu CJ, Chang $\mathrm{CH}$, Hsu HC. The epidemiology of traumatic humeral shaft fractures in Taiwan. Int Orthop 2009;33:463-7. DOI: 10.1007/s00264-008-0537-8.

3. Rose SH, Melton LJ , Morrey BF, Ilstrup DM, Riggs BL. Epidemiologic features of humeral fractures. Clin Orthop 1982 Aug;(168):24-30.

4. Bucholz RW, Heckman JD, Court-Brown CM. Fractures of the shaft of the humerus. In: Rockwood and Green's fractures in adults. 6th ed. Philadelphia: Lippincott Williams \& Williams; 2006; 1:1118-62.

5. Sarmiento A, Waddell JP, Latta LL. Diaphyseal humeral fractures: Treatment options. Instr Course Lect. 2002; 51:257-69.

6. Raghavendra S, Bhalodiya HP. Internal fixation of fractures of the shaft of the humerus by dynamic compression plate or intramedullary nail: A prospective study. Indian J Orthop. 2007 Jul-Sep; 41(3):214-8. DOI: 10.4103/0019-5413.33685.

7. Toivanen JA, Nieminen J, Laine HJ, Honkonen SE, Jarvinen MJ. Functional treatment of closed humeral shaft fractures. Int Orthop 2005;29(1):10-13. DOI: 10.1007/s00264-004-0612-8.

8. Sarmiento A, Kinman P, Galvin E, Schmiff RH, Phillips JG. Functional bracing of fractures of shaft of humerus. J Bone Joint Surg Am 1977 Jul;59(5):596601.

9. Balfour GW, Mooney V, Ashby ME. Diaphyseal fractures of the humerus treated with a readymade brace. J Bone Joint Surg Am 1982;64(1):11-13.

10. Mast JW, Spiegel PG, Harvey JP, Harrison C. Fractures of the humeral shaft: A retrospective study of 240 adult fractures. Clin Orthop Relat Res. 1975 Oct;(112):254-62.

11. Singisetti K, Ambedkar M. Nailing versus plating in humerus shaft fractures:A prospective comparative 
study. International Orthopaedics. 2010;34:571-6. DOI: 10.1007/s00264-009-0813-2.

12. Changulani M, Jain UK, Keswani T, Comparison of the use of the humerus intramedullary nail and dynamic compression plate for the management of diaphyseal fractures of the humerus: A randomized controlled study. Int Orthop. 2007;31:391-5. DOI: 10.1007/s00264-006-0200-1.

13. Matt W, Brian P, Brian B, Jordan B, Jeffrey VG, Mark M. Humeral shaft fractures: a review. J Shoulder Elbow Surg 2011;1-12. DOI: 10.1016/j.jse.2010.11.030.

14. McCormack RG, Brein D, Buckley RE, Mckee MD, Powell J, Schemitsch EH. Fixation of fractures of the shaft of the humerus by dynamic compression plate or intramedullary nail: A prospective randomized trial. J Bone Joint Surg Br. 2000 Apr; 82-B(3):336-9.

15. Lin J. Treatment of humeral shaft fractures with humeral locked nail and comparison with plate fixation. J Trauma 1998 May;44(5):859-64.

16. Chapman JR, Henley MB, Agel J, Benca PJ. Randomized prospective study of humeral shaft fracture fixation: Intramedullary nails versus plates. J Orthop Trauma. 2000 Mar-Apr; 14(3):162-6.

17. Gautier E, Perren SM. Limited contact dynamic compression plate (LC-DCP):Biomechanical research as basis to new plate design. Orthopade. 1992 Feb;21(1):11-23.

18. Perren SM, Klaue K, Pohler O, Predieri M, Steinemann S, Gautier E. The limited contact dynamic compression plate (LC-DCP). Arch Orthop Trauma Surg. 1990;109(6):304-10.

19. Rodriguez-Merchan EC. Compression plating versus hackethal nailing in closed humeral shaft fractures failing non operative reduction. J Orthop Trauma 1995 Jun;9(3):194-7.
20. Antony Denard Jr et al. Outcome of Nonoperative Vs Operative treatment of humeral Shaft fractures:A Retrospective study of 213 patient. Orthopaedics 2010 Aug;33(8):25-31. DOI: 10.3928/01477447-2010062516.

21. Van Midendorp $\mathbf{J} \mathbf{J}$ et al. Outcomes following operative and non-operative management of humeral midshaft fractures:A prospective, observational cohort study of 47 patients. Eur $\mathrm{J}$ trauma Emerg surg 2011;37:287-96. DOI: 10.1007/s00068-011-0099-0.

22. Andre R .Spiguel, Robert J.Steffner. Humeral shaft fratures. Curr Rev Musculoskelet Med. 2012 Sep;5(3):177-83. DOI: 10.1007/s12178-012-9125-z.

23. Benegas $\mathrm{E}$ et al. Comparative, prospective and randomized study of humeral shaft fractures requiring surgical treatment: bridging plate versus locked intramedullary nail. Acta Ortopedica Brasileira. 2007; $15(2)$. http://dx.doi.org/10.1590/s141378522007000200006 .

24. Shah S M, Ajganokar A R. Diaphyseal Fractures of humerus: Intramedullary nail versus plate fixation. Bombay Hospital Journal. 2012;54(1):18.

25. Kesemenli C C, Subasi M, Arslan H, Necmioglu S, Kapukaya A.Comparison between the results of intramedullary nailing and compression plate fixation in the treatment of humerus fractures. Acta Orthop Traumatol Turc 2003;37(2):120-5.

26. Venkatesh Gupta S K, Kumar K M, Reddy K R, Guru Prasad S S, Gopichand K. Comparative study of management of humeral diaphyseal fractures by DCP plate and IMIL nail. Journal of evolution of medical and dental sciences 2014 Feb;3(7):1782-88. DOI: 10.14260/jemds/2014/2058.

27. Denies E, Nijs S, Sermon A, Broos P. Operative treatment of humeral shaft fractures:A comparison of plating and intramedullary nailing. Acta Orthop Belg. 2010;76(6):735-42.

\section{How to cite this article?}

Elango M, Manoharan M, Sureshraj P, Justin Moses C, Murugan A. Functional outcome of diaphyseal humerus fractures treated with LC-DCP and intramedullary nail - a comparative study. Int J Med Res Rev 2015;3(10):1193-1200. doi: 10.17511/ijmrr.2015.i10.218. 